\title{
Competency Improvement Needs of Farmers in Soil Erosion Prevention and Control for Enhancing Crop Production: Case Study of Kogi State, Nigeria
}

\author{
F. M. Onu, Abu Mohammed \\ Agricultural Unit, Department of Vocational Teacher Education, University of Nigeria, Nsukka, Nigeria \\ Email: maduekefrancis@gmail.com
}

Received 3 July 2014; revised 16 August 2014; accepted 9 September 2014

Copyright (C) 2014 by authors and Scientific Research Publishing Inc.

This work is licensed under the Creative Commons Attribution International License (CC BY). http://creativecommons.org/licenses/by/4.0/

(c) (i) Open Access

\begin{abstract}
This study investigated the competency improvement needs of farmers in soil erosion prevention and control for enhancing crop production in Kogi state of Nigeria and was carried out between January and June, 2014. The study adopted descriptive survey research design and was guided by two research questions. The study found out that farmers needed improvement on 37 cultural practices as follows: 10 competencies in mulching, 12 in cover cropping, 8 in strip cropping, 7 in contour farming and $\mathbf{4 5}$ mechanical field practice as follows: 10 competencies in contour bonding, 11 in terracing, 12 in channeling and 11 in tunneling for success in soil erosion prevention and control. The study recommended the organization of rural based programmes for the training of farmers in the practice identified to enhance their competencies in soil erosion prevention and control for increased crop production.
\end{abstract}

\section{Keywords}

\section{Soil Erosion, Erosion Control, Competency, Crop Production, Erosion Prevention}

\section{Introduction}

Soil is essential for the survival of all living things as it provides nutrients for growth of crops that most animals directly or indirectly depend on for existence. Soil is defined as the natural body of loose unconsolidated materials which constitutes a layer of several meters deep on the earth surface [1]. For the soil to continue meeting the demand of crops for nutrient availability, it has to be protected and conserved from such menace as erosion. 
Soil erosion is the wearing away of the land surface by water, wind, ice or other geological agent. Soil erosion is a natural or anthropogenic-influenced process by which rock and soil are broken loose from earth surface at one location and moved to another [2]. Soil erosion expressed as leaching is observed in the tropics as the washing away of the rich top soil by such agents as wind or water so that the sub soil which cannot productively support crops growth is exposed [2]. Soil erosion is of two phases: geological and accelerated erosion [1]. Geological erosion takes place under natural condition when the land surface and natural vegetation have not been interfered with by human activities while accelerated erosion occurs when geological erosion is speeded up as a result of human activities [1].

Soil erosion is influenced by certain factors which includes: the amount, distribution and intensity of rainfall, the topography of the land, the face of prevailing wind, soil physical condition or characteristics like structure and texture, extent of vegetative cover, the type crop grown, and the system of husbandry adopted [3]. Crop growing farmers are expected to possess skills in soil erosion prevention and control in order to conserve the soil and increase their agricultural productivity. For a largely organized community to remain agrarian over decades, the greatest impact of erosion which lies in the volumetric loss of soil, decrease in the soil nutrient capacity, moisture retention capacity, organic matter content and depth of the soil with resultant effect on soil being seriously impoverished will need to be curtailed as these negatively influence crop production [2]. This situation could be achieved with effective soil erosion prevention and control skills in cultivation.

Soil erosion prevention refers to those anticipatory measures geared towards avoiding the occurrence or control of any type of soil erosion [4]. Such measures include cultural and mechanical approaches. However, preference should be given to agronomic treatment or cultural measures in utilizing the role of vegetation to prevent erosion, largely because cultural measures such as mulching, cover cropping, strip cropping, contour farming are less expensive and deal directly with reducing raindrop impact, increasing infiltration, reducing runoff volume and decreasing wind and water velocity, and it is easier to fit such practices into the existing farming system [5]. Soil erosion control on the other hand refers to the act of restraining the various forms of wind, water and mining erosion from having threatening effect on cultivated soil [4]. Some identified mechanical field practices to help control and prevent erosion include contour bonds, terracing, construction of channel and tunnel as these practices controls movement of water and wind over the soil surface [5].

However competent levels of the farmers ensure effective utilization of these practices on their farm and their environment for soil erosion prevention and control. To be competent means that the individual has acquired the knowledge and skills required in order to perform successfully at a specific proficiency level in the given task [6]-[8]. Farming in Kogi State is associated with shifting cultivation and continuous cropping. The farm lands are owned by individual farmers through inheritance and lease holding which is renewable annually. The size of the farm holding is usually small and becomes depleted in fertility due to crop removal and other degrading agencies such as soil erosion. Occasion of erosion is rampart in the farming lands with limited efforts being exhibited by the farmers to curtain the menace. This reveals that the farmers need improvement in their existing attempts for soil erosion prevention and control measures to enhance their agricultural production activities and implies that there is a need for improvement. Improvement is to make something or somebody better than before [9]. Improvement in existing skills or practices ensures better performance. If farmers in Kogi state improve their competencies in soil erosion prevention and control approach, they will perform better and ensure increase in crop production. Unfortunately, areas in soil erosion prevention and control where the farmers in Kogi state require improvement have not been determined empirically.

The purpose of the study therefore was to identify competency improvement needs of farmers in soil erosion prevention and control for enhancing crop production in Kogi State, Nigeria. Specifically, the study sought to identify (i) competencies in cultural and (ii) mechanical field practices which could help farmers prevent and control erosion menace in Kogi state for increased food production.

\section{Methodology}

The study which was carried out in Kogi state sought to address the competency improvement needs of farmers in soil erosion prevention and control for enhancing crop production. Descriptive survey research design was adopted for the study. The population for the study was 1044, made up of 834 crop farmers and 210 Agricultural Extension Agents registered with the State Ministry of Agriculture in Kogi State. The sample for the study was 628, made up of 418 farmers and 210. The entire population of the extension agents was studied while stratified 
random sampling techniques were used to select $40 \%$ of the farmers. An 82 item questionnaire was developed from literature reviewed and used for data collection. The questionnaire had two response categories for needed and current performance level of the farmers. The need category had four response options of Highly Needed (HN), Averagely Needed (AN), Slightly Needed (SN), and Not Needed (NN) and was administered on the extension agents while the performance category had four response options of High Performance (HP), Average Performance (AP), Low Performance (LP), and Poor Performance (PP) and administered on the farmers. Each of the response options had weighted values of 4, 3, 2 and 1 respectively. Three experts face validated the instrument, of which two were from the Department of Vocational Teacher Education and one from Soil Science Department, University of Nigeria, Nsukka. Cronbach Alpha method was used to determine the internal consistency of the instrument and a co-efficient of 0.89 was obtained. 628 copies of the instrument were administered to the respondents with the help of four research assistants, 572 copies were retrieved (representing $91 \%$ retrieval rate) while 554 were properly completed thus found useful for analyzed.

Weighted mean and Improvement Need Index (INI) were used to answer the research question. The Improvement Need Index (INI) was used to identify the area of skills in soil erosion prevention and control measure where farmers needed improvement as follows: $\left(\bar{X}_{n}\right)$-the weighted mean of needed category; $\left(\bar{X}_{P}\right)$ weighted mean of performance category; $\left(\bar{X}_{n}-\bar{X}_{P}\right)$ —the differences between the two mean. The difference for item gives the Need Gap (NG) Value which is compared with the Improvement Needed Index (INI) for decision making as follows: where the difference was zero or negative, it indicates that there was no need for improvement as the level of performance $\left(\bar{X}_{P}\right)$ is equal to or greater than (respectively) the level at which the competencies are needed $\left(\bar{X}_{n}\right)$; where the difference was positive, there was need for improvement, because the level of performance of the farmer is less than the level at which the competency in the items is needed.

\section{Results}

The results of the study are presented in Table 1 and Table 2.

The data in Table 1 revealed that the Need Gap (NG) values of all the 37 items of 4 clusters ranged from 0.21 - 1.87 and were all positive. This indicated that the farmers needed improvement in all the 37 cultural practices in soil erosion prevention and control.

The data in Table 2 revealed that the Need Gap (NG) values for all the 45 items of 4 clusters ranged from 0.76 - 2.66 and were all positive. This indicated that the farmers needed improvement in the 45 mechanical field practice items for soil erosion control and prevention in Kogi State.

The results of the study showed that farmers needed improvement on 37 cultural practices (10 competency improvement in mulching, 12 in cover cropping, 8 in strip cropping and 7 in contour farming) and 45 mechanical field practice (10 competency improvement in contour bonding, 11 in terracing, 12 in channeling and 11 in tunneling). The findings of this study is in agreement with the findings of [10] in a study carried out on requisite skills in soil conservation required for equipping secondary school graduate for profitable crop production in Abia State where it was found out that secondary school graduate required 13 skill item in tillage and 18 in soil erosion prevention and control, among others. The findings of this study also conform to that of [11] in a study on soil conservation skills required by students of Agriculture in Colleges of Education for effective teaching in South Eastern, Nigeria. The competency needs identify include 39 skills in soil erosion prevention and control, 11 skills in drainages and 32 skills in crop rotation, among others. The observation and findings of the authors cited in their various studies helped to validate the findings of this study.

\section{Conclusion}

The continuous occasion of soil erosion in any farming region is a known threat to productive crop cultivation. Its occurrence and impacts in farming land are of various degrees and efforts should be made to prevent and control it for enhanced crop production. To help prevent and control its rise in the state, simple and cost effective practices can be incorporated into the traditional farming practices while the existing measures can be improved in order to enhance crop production for increased food security in the state and beyond. The study has identified measures where farmers need improvement in soil erosion prevention and control. The study thus recommends the organization of rural based programmes for the training of farmers in the 82 practice identified by authorities overseeing affairs of agriculture and food production in the state, such as the Kogi State Ministry of Agricultural and Natural resources as well as other well-meaning international and indigenous Non-Governmental 
Table 1. Need gap (NG) analysis of the respondents on the improvement needs of farmers in cultural practices for soil erosion prevention in Kogi state ( $\mathrm{N}=554: 351$ farmers and 203 agricultural extension agents)

\begin{tabular}{|c|c|c|c|c|c|}
\hline $\mathbf{S} / \mathbf{N}$ & Competencies in: & $\bar{X}_{n}$ & $\bar{X}_{p}$ & $\bar{X}_{n}-\bar{X}_{p}=\mathbf{N G}$ & $\mathbf{R}$ \\
\hline & Mulching & & & & \\
\hline 1 & Collect mulch materials such as grasses, leaves, sawdust, organic manure etc. & 3.76 & 2.25 & 1.50 & IN \\
\hline 2 & Chop off mulch materials for easy usage & 3.79 & 2.34 & 1.45 & IN \\
\hline 3 & Spread the leaves, grasses, sawdust, crop residues to dry & 3.86 & 2.27 & 1.58 & IN \\
\hline 4 & Spread the material at the base of the crops (partial mulching) & 3.78 & 2.45 & 1.34 & IN \\
\hline 5 & Spread the materials on the ridge, bed and furrow (complete mulching) & 3.78 & 2.45 & 1.34 & IN \\
\hline 6 & Maintain mulch layer of 5 - $10 \mathrm{~cm}$ for effective coverage & 3.78 & 2.28 & 1.50 & IN \\
\hline 7 & Cap/shed young tendrils or seedlings with much material & 3.64 & 2.13 & 1.50 & IN \\
\hline 8 & Spread mulch on soil loosened by tilling or weeding & 3.72 & 2.43 & 1.27 & IN \\
\hline 9 & Spread plastics or paper sheet over cultivated patch or round tree seedling & 3.81 & 2.08 & 1.72 & IN \\
\hline \multirow[t]{2}{*}{10} & Leave space between plant and mulch material & 3.64 & 1.90 & 1.73 & IN \\
\hline & Cover Cropping & & & & \\
\hline 11 & Identify the site for cover cropping & 3.81 & 2.63 & 1.18 & IN \\
\hline 12 & Prepare the site with suitable implements & 3.68 & 3.48 & 0.21 & IN \\
\hline 13 & Select appropriate cover crops to be planted & 3.64 & 2.73 & 0.21 & IN \\
\hline 14 & Test for seed viability & 3.91 & 2.63 & 1.27 & IN \\
\hline 15 & Moderately till the soil with suitable implement & 3.66 & 2.21 & 1.45 & IN \\
\hline 16 & Broadcast the seed on the tilled land (option) & 3.67 & 2.79 & 0.67 & IN \\
\hline 17 & Spot plant the seed in rolls (option) & 3.72 & 2.54 & 1.18 & IN \\
\hline 18 & Plant cover crops as mixed food crops & 3.67 & 2.84 & 0.83 & IN \\
\hline 19 & Plant cover crops as green manure & 3.77 & 2.74 & 1.03 & IN \\
\hline 20 & Observe seed germination rate & 3.59 & 2.69 & 0.90 & IN \\
\hline 21 & Guard against fire outbreak, pest and diseases & 3.46 & 2.79 & 0.68 & IN \\
\hline \multirow[t]{2}{*}{22} & Prevent weed growth & 3.63 & 2.78 & 0.86 & IN \\
\hline & Strip Cropping & & & & \\
\hline 23 & Identify area of land for strip cropping & 4.00 & 2.67 & 1.33 & IN \\
\hline 24 & Draw plan for the strip & 3.87 & 2.46 & 1.51 & IN \\
\hline 25 & $\begin{array}{l}\text { Collect dense fibrous rooting crops such as perennial, legumes, grasses or } \\
\text { forage crops }\end{array}$ & 3.96 & 2.46 & 1.51 & IN \\
\hline 26 & Layout strip on long slope subject to sheet rill erosion & 3.93 & 2.89 & 1.05 & IN \\
\hline 27 & Construct strip not wider than $30 \mathrm{~m}$ and not narrower than $15 \mathrm{~cm}$ & 3.93 & 2.44 & 1.49 & IN \\
\hline 28 & Cultivate across the slope rather than along the slope & 3.88 & 2.79 & 1.09 & IN \\
\hline 29 & Plant at right angle to the prevailing wind & 3.94 & 2.78 & 1.16 & IN \\
\hline \multirow[t]{2}{*}{30} & Alternate strips crop such as corn and potatoes with hay and grains & 3.85 & 2.88 & 0.97 & IN \\
\hline & Contour Farming & & & & \\
\hline 31 & Clear the site of existing vegetation & 3.86 & 2.89 & 0.97 & IN \\
\hline 32 & Observe the slope and its steepness & 3.84 & 3.29 & 0.55 & IN \\
\hline 33 & Measure the distance of the contour within the farm & 3.91 & 2.79 & 1.12 & IN \\
\hline 34 & Construct the ridges in spiral form along the contour & 3.81 & 2.17 & 1.64 & IN \\
\hline 35 & Plant the crop on the ridges & 3.95 & 2.08 & 1.87 & IN \\
\hline 36 & Construct diversion ditches and water ways between field with high slopes & 3.80 & 2.62 & 1.18 & IN \\
\hline 37 & Plant grass along the water way to prevent under washing & 3.96 & 2.25 & 1.71 & IN \\
\hline
\end{tabular}

$\bar{X}_{n}=$ Mean of Needed Category, $\bar{X}_{p}=$ Mean of Performance Category, IN = Improvement Needed, INN = Improvement Not Needed, NG = Need Gap, R = Remark. 
Table 2. Need gap (NG) analysis of the respondents on the improvement needs of farmers in mechanical field practices for soil erosion prevention and control in Kogi state ( $N=554: 351$ farmers and 203 agricultural extension agents).

\begin{tabular}{|c|c|c|c|c|c|}
\hline $\mathrm{S} / \mathrm{N}$ & Competencies in: & $\bar{X}_{n}$ & $\bar{X}_{p}$ & $\bar{X}_{n}-\bar{X}_{p}=\mathrm{NG}$ & $\mathbf{R}$ \\
\hline & Contour Bunding & & & & \\
\hline 1 & Identify the erosion site & 4.00 & 2.69 & 1.31 & IN \\
\hline 2 & Prepare the site for contour bonding & 3.96 & 2.69 & 1.27 & IN \\
\hline 3 & Observe the contour and its slope & 3.96 & 2.41 & 1.55 & IN \\
\hline 4 & Measure the contour and its slope & 3.93 & 2.56 & 1.37 & IN \\
\hline 5 & Lay out contour using stake driven into the ground on point of equal elevation & 3.96 & 2.39 & 1.57 & IN \\
\hline 6 & Determine the elevation using farm level or Abney level & 3.95 & 2.45 & 1.50 & IN \\
\hline 7 & Construct the contour bund using suitable implement & 3.92 & 2.39 & 1.52 & IN \\
\hline 8 & Space the contour bund at $10-20 \mathrm{~cm}$ interval & 3.79 & 1.95 & 1.84 & IN \\
\hline 9 & Make the contour bund during period of low rainfall & 3.93 & 1.72 & 2.20 & IN \\
\hline 10 & Plant crops on the bunds & 3.94 & 1.52 & 2.43 & IN \\
\hline 11 & $\begin{array}{l}\text { Stabilize the contour bund with vegetation to withstand heavy rainstorm } \\
\text { Terracing }\end{array}$ & 4.00 & 1.46 & 2.54 & IN \\
\hline 12 & Clear the farmland of existing vegetation & 3.93 & 1.63 & 2.30 & IN \\
\hline 13 & Survey the farmland and note the slope and gullies & 3.92 & 3.16 & 0.76 & IN \\
\hline 14 & Plan the terrace according to the drainage unit of the farm & 4.00 & 2.54 & 1.46 & IN \\
\hline 15 & Mark out position for the construction of the terrace & 3.94 & 1.63 & 2.31 & IN \\
\hline 16 & Construct the terrace with appropriate implement & 3.91 & 1.82 & 2.09 & IN \\
\hline 17 & Construct the terrace by breaking the slope into steps & 3.88 & 1.61 & 2.27 & IN \\
\hline 18 & Place barriers such as sandbag, log of wood & 3.96 & 1.46 & 2.50 & IN \\
\hline 19 & Arrange for the maintenance of the terrace & 3.96 & 1.46 & 2.50 & IN \\
\hline 20 & Construct diversion channel to remove excess water & 3.78 & 1.45 & 2.34 & IN \\
\hline 21 & Plant crops on the terrace & 4.00 & 1.88 & 2.12 & IN \\
\hline \multirow[t]{2}{*}{22} & Plant grass along the diversion channel to prevent under wash & 3.96 & 1.53 & 2.43 & IN \\
\hline & Channeling & & & & \\
\hline 23 & Prepare the site for channeling & 3.78 & 1.13 & 2.24 & IN \\
\hline 24 & Survey the farmland & 3.78 & 2.83 & 0.95 & IN \\
\hline 25 & Determine the slope, length and width of the slope & 3.81 & 1.65 & 2.17 & IN \\
\hline 26 & Measure out the length and width of the slope & 3.76 & 1.52 & 2.24 & IN \\
\hline 27 & Determine the channel depth & 3.81 & 1.43 & 2.39 & IN \\
\hline 28 & $\begin{array}{l}\text { Build the channel incorporation with adjacent land owner for common runoff } \\
\text { outlet system }\end{array}$ & 3.79 & 1.43 & 2.36 & IN \\
\hline 29 & Excavate the channel with relevant implement & 3.73 & 1.45 & 2.28 & IN \\
\hline 30 & Build the channel using concrete or cement block or corrugated metals & 3.74 & 1.45 & 2.28 & IN \\
\hline 31 & Install drop-check structure at interval along the channel to reduce the rate of flow & 3.74 & 1.35 & 2.39 & IN \\
\hline 32 & Arrange for a permanent maintenance & 3.72 & 1.53 & 2.19 & IN \\
\hline 33 & Grass the outlet to prevent wash & 3.64 & 1.53 & 2.11 & IN \\
\hline \multirow[t]{2}{*}{34} & Dig catchments pits beside farmland & 3.72 & 1.53 & 2.20 & IN \\
\hline & Tunneling & & & & \\
\hline 35 & Survey farmland and note the direction of water flow and its stand & 3.79 & 1.42 & 2.37 & IN \\
\hline 36 & Draw plan for the tunneling & 3.73 & 1.33 & 2.40 & IN \\
\hline 37 & Measure out the position for the installation of tunnel & 3.79 & 1.32 & 2.48 & IN \\
\hline 38 & Build the tunnel with concrete materials & 3.69 & 1.41 & 2.28 & IN \\
\hline 39 & Excavate soil from the measured position & 3.70 & 1.26 & 2.42 & IN \\
\hline 40 & Build the tunnel when rainfall is low & 3.62 & 1.21 & 2.42 & IN \\
\hline 41 & Install the tunnel in the excavated position & 3.71 & 1.32 & 2.39 & IN \\
\hline 42 & Cover the tunnel with top soil & 3.81 & 1.15 & 2.66 & IN \\
\hline 43 & Allow water to pass through the tunnel & 3.81 & 1.15 & 2.66 & IN \\
\hline 44 & Connect the tunnel to the nearest convenient outlet & 3.72 & 1.35 & 2.35 & IN \\
\hline 45 & Plant grasses along the outlet to prevent under wash & 3.58 & 1.27 & 2.31 & IN \\
\hline
\end{tabular}

$\bar{X}_{n}=$ Mean of Needed Category, $\bar{X}_{P}=$ Mean of Performance Category, $\mathbf{I N}=$ Improvement Needed, INN = Improvement Not Needed, NG = Need Gap, R = Remark. 
Organizations in the state and Nation. Workshops and re-training could also be organized for extension agents in the state to enhance their ability to teach the farmers the identified competency needs.

\section{References}

[1] Olaitan, S.O. and Lombin G. (1985) Introduction to Tropical Soil Science. Macmillan Publishers, Lagos.

[2] Osinem, E.C. (2005) Environmental Education in Agriculture. Cheston Agency Ltd., Enugu.

[3] Anyanwu, A.C., Anyanwu, B.O. and Anyanwu, V.O. (2003) A Text Book for Agricultural Science for Schools and Colleges. Afp Africana Feb Publishers Ltd., Onitsha.

[4] Olaitan, S.O. (2005) Soil Erosion Management Education. University of Nigeria Nsukka. (Unpublished)

[5] Morgan, R.P. (1996) Soil Erosion and Conservation. Longman Group Ltd., London.

[6] Sullivan, R.C. (1995) The Competency Based Approach to Training. JHP’EGO Corporation, Scotland.

[7] Olaitan, S.O. (2003) Understanding Curriculum. Ndudim Printing and Publishing, Nsukk.

[8] Olaitan, S.O., Asogwa, V.C. and Abu, M. (2011) Technology Competency Training Modules Required by Secondary School Graduates in E-Waste Management in Agribusiness. A paper presented at the Institute of Education, University of Nigeria Nsukka.

[9] Hornby, A.S. (2006) Oxford Learners Dictionary of Current English. Oxford University Press, London.

[10] Nwankwo, A. (2007). Requisite Skills in Soil Conservation Required for Equipping Secondary School Graduate for Profitable Crop Production in Abia State. Unpublished M.Ed Thesis, Department of Vocational Teacher Education, University of Nigeria, Nsukka.

[11] Azunku, P.N. (2008) Soil Conservation Skills Required by Students of Agriculture in Colleges of Education for Effective Teaching in South Eastern, Nigeria. Unpublished M.Ed Thesis, University of Nigeria, Nsukka. 
Scientific Research Publishing (SCIRP) is one of the largest Open Access journal publishers. It is currently publishing more than 200 open access, online, peer-reviewed journals covering a wide range of academic disciplines. SCIRP serves the worldwide academic communities and contributes to the progress and application of science with its publication.

Other selected journals from SCIRP are listed as below. Submit your manuscript to us via either submit@scirp.org or Online Submission Portal.
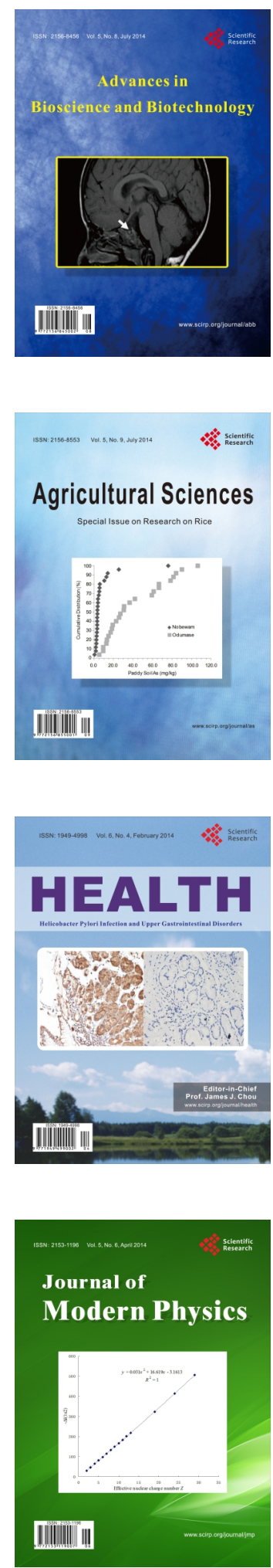
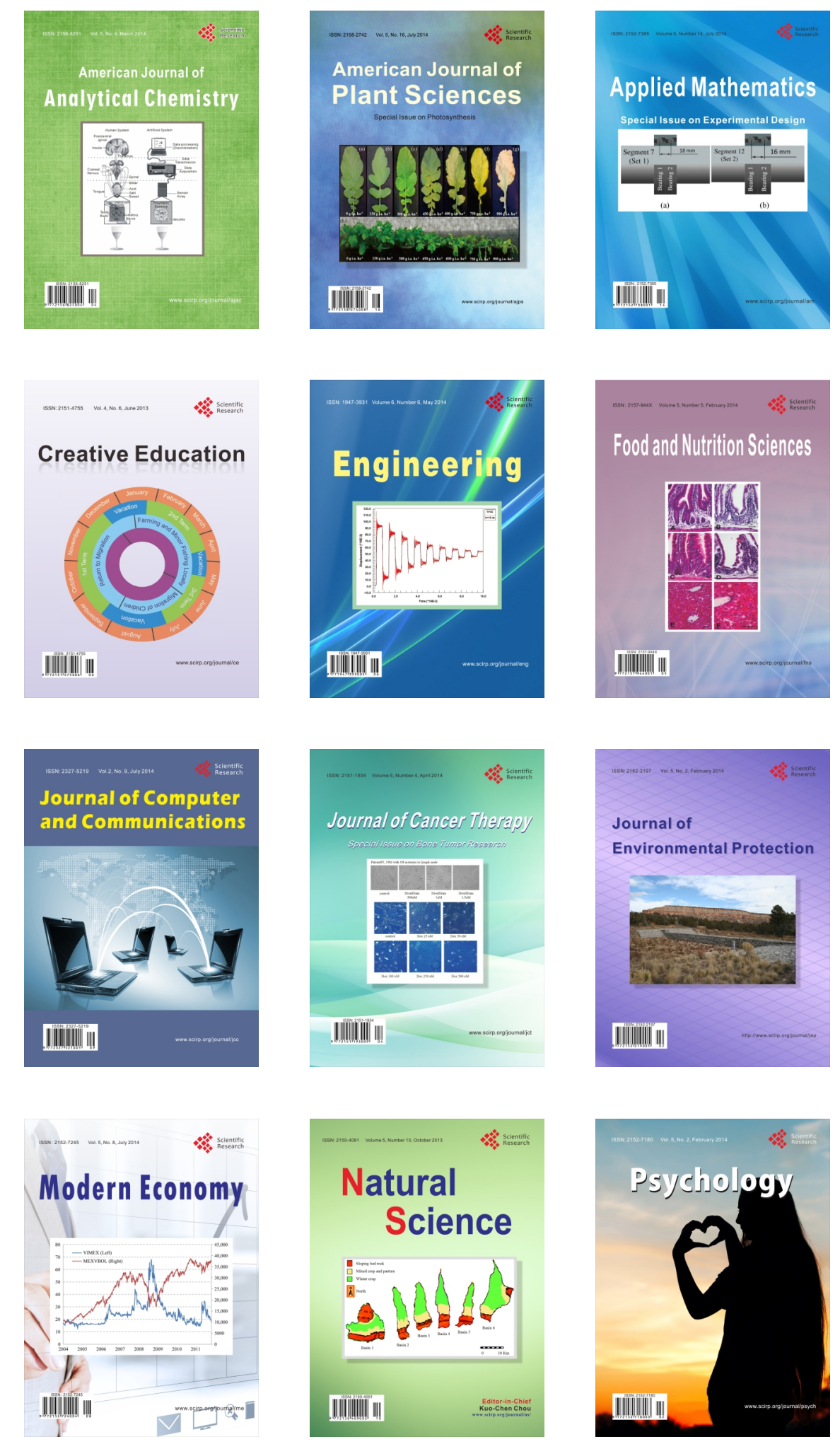